\title{
Preferred Orientation in Microstructures of Eutectics Between Compounds
}

\author{
JOHN W. MOORE* and LAWRENCE H. VAN VLACK \\ Department of Chemical and Metallurgical Engineering, The University of Michigan, Ann Arbor, Michigan 48104
}

\begin{abstract}
The microstructures of eutectics between compounds were studied for systems $\mathrm{MnO}-\mathrm{MnS}, \mathrm{NaCl}-\mathrm{NaF}, \mathrm{NaBr}-\mathrm{NaF}$, $\mathrm{LiF}-\mathrm{NaF}$, and FeO-FeS. With the exception of FeS, all the compounds had the $\mathrm{NaCl}-$ type structure. In the systems having only $\mathrm{NaCl}$-type structures, the lamellas of the two eutectic phases had matching crystal orientations. There was less consistency among the eutectic systems, however, than between the phase pairs. The crystal growth directions in all five systems were different, and no more than two of the systems had the same set of interfacial planes. One must conclude that the two phases within a eutectic of compounds do not solidify independently of one another. It is suggested that the two phases of an $\mathrm{NaCl}$-type eutectic pair crystallize as a "single" ionic crystal with imperfections present to accommodate
\end{abstract} the dimensional mismatch.

\section{Introduction}

$\mathbf{P}^{2}$ ANN'S ${ }^{1}$ analysis of single phase solidification during zonemelting, extended by Chalmers and his associates, ${ }^{2,3}$ has been applied by several investigators ${ }^{4-10}$ to the study of solidification in simple two-phase eutectic systems. Studies have been confined primarily to low melting point metallic systems except for work on alkali halide eutectics by Hellawell et al. ${ }^{11-14}$

Microstructures in unidirectionally solidified, high-purity, two-phase metallic eutectics generally consist of (1) rods of one of the phases distributed uniformly in a matrix of the second, or (2) alternating plates of the two eutectic phases in a lamellar structure. In both cases, the discontinuous rods or plates appear in a regularly spaced array with their longer dimensions oriented in the direction of solidification and normal to the solidification front

Specific crystallographic relations exist between the two phases in many unidirectionally solidified eutectic pairs. Investigators, however, have not always reported identical preferred growth directions and interfacial planes for the same eutectic systems. The factors which cause orientations to be preferred are not yet well understood.

This paper describes the results of the investigation of the relative crystallographic orientation of the lamellar or rodlike phases in the unidirectionally solidified eutectics of five systems involving compounds $\mathrm{MnO}-\mathrm{MnS}, \mathrm{NaCl}-\mathrm{NaF}, \mathrm{NaBr}-$ $\mathrm{NaF}, \mathrm{LiF}-\mathrm{NaF}$, and FeO-FeS. With the exception of FeS, all the compounds have the same NaCl-type structure. The lamellar microstructure obtained by the authors for the $\mathrm{MnO}-\mathrm{MnS}$ eutectic is illustrated in Fig. 1.

\section{Experimental Procedure}

The $\mathrm{MnO}$ was prepared by reducing $99.9 \%$ pure $\mathrm{MnO}_{2}$ in hydrogen at $950^{\circ} \mathrm{C}$. The MnS was prepared by deoxidizing $98.8 \%$ pure $\mathrm{MnSO}_{4} \cdot \mathrm{H}_{2} \mathrm{O}$ by sulfur after the method of Chao et $a .^{15}$ The FeS was prepared by reacting stoichiometric quantities of $99.98 \%$ iron wire and sulfur in an evacuated and sealed Vycor glass tube at $880^{\circ} \mathrm{C}$. The other raw materials were reagent grade alkali halides and $\mathrm{Fe}_{2} \mathrm{O}_{3}$.

The above materials were mixed as powders to provide the proper eutectic compositions and melted in Ferrovac iron

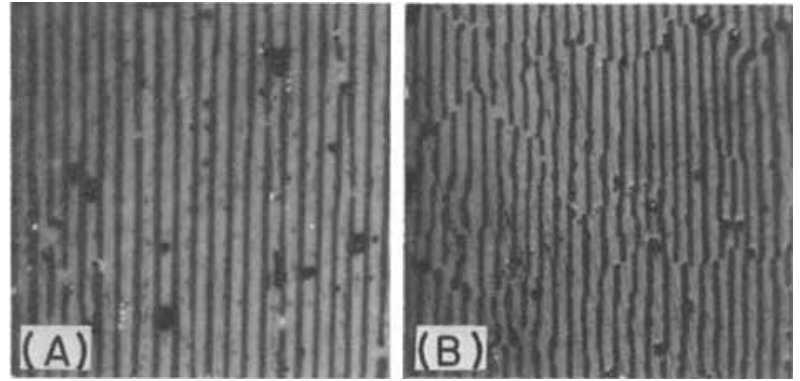

Fig. 1. Photomicrographs of transverse $(A)$ and longitudinal $(B)$ cross sections of a typical $\mathrm{MnO}$-MnS unidirectionally solidified lamellar eutectic. (Light, MnS; dark, MnO. $\times 500$.

crucibles (for the MnO-MnS and FeO-FeS entectics) or in spectrographic grade graphite crucibles (for the alkali halide eutectics). The ingots were unidirectionally solidified under an argon atmosphere by drawing them vertically from the bottom of a silicon carbide resistance furnace, using an Instron crosshead drive at rates from 9 to $50 \times 10^{-5} \mathrm{~cm} / \mathrm{sec}$

The resulting ingots were sectioned, polished transversely and longitudinally, and carefully photographed in the areas selected for X-ray study. Latie back-reflection X-ray photographs were used to determine the relations among the crystal orientations, lamellar interfaces, and growth directions. Chips were then cleaved from the same regions and mounted on the goniometer head of a Buerger precession X-ray camera. These cleavage chips were oriented with respect to the microstructure by optical reflections from previously polished and cleaved orthogonal faces. Zero-level precession X-ray patterns from two or three orthogonal directions of these chips provided the precise relative relations of the two eutectic phases (Fig. 2). Several samples were taken from each eutectic microstructure.

\section{Results}

The interfacial planes between the lamellar platelets had a low index and high density in each of the entectic systems studied (Table I). Low index orientations also defined the growth directions and directions within the lamellas perpendicular to the growth direction (Table I and Figs. 3 and 4). The crystallographic orientations were the same for both phases of the eutectic pair in the systems having only $\mathrm{NaCl}$ structures (MnO-MnS, $\mathrm{NaCl}-\mathrm{NaF}, \mathrm{NaBr}-\mathrm{NaF}$, and $\mathrm{LiF}-$

Received February 15, 1967

Based on a thesis submitted by J. W. Moore for the Ph.D. degree at The University of Michigan.

This study was sponsored by the Office of Naval Research, Metals Branch, under Contract Nonr-1224(47).

At the time this work was done, the writers were, respectively, graduate student, and professor and chairman, Department of Chemical and Metallurgical Engineering, The University of Michigan.

* Now senior research engineer, Pioneering Research Laboratory, Textile Fibers Department, E. I. du Pont de Nemours, Inc., Wilmington, Delaware 19898. 


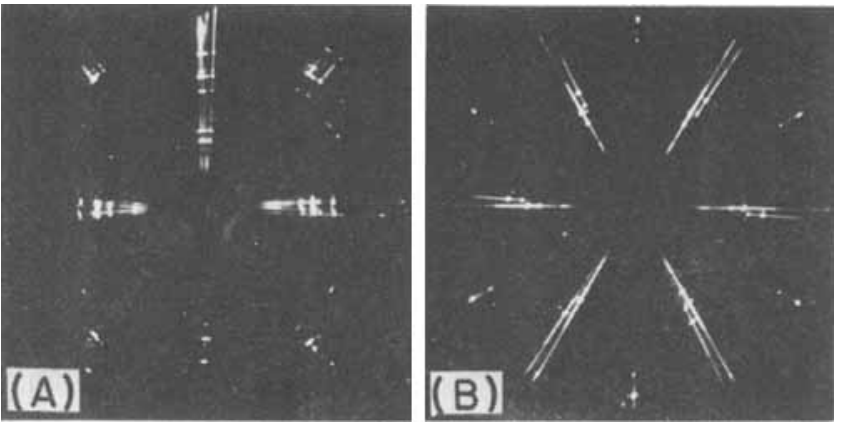

Fig. 2. Buerger precession zero-level X-ray transmission photographs of a lamellar $\mathrm{MnO}$-MnS eutectic $(A)$ parallel to [112] growth direction, and $(B)$ parallel to $\left[\begin{array}{lll}1 & 1\end{array}\right]$ interface normal. (Spots on larger radius represent $\mathrm{MnO}$ phase with a smaller unit cell size. Twist, $6^{\circ}$; tilt, $3^{\circ}$.)

NaF). However, two sets of planes served as the mutual interface [(111) for $\mathrm{MnO}-\mathrm{MnS}$ and $\mathrm{LiF}-\mathrm{NaF}$, and (110) for $\mathrm{NaCl}-\mathrm{NaF}$ and $\mathrm{NaBr}-\mathrm{NaF}$. None of these four systems had the same growth direction. In the FeO-FeS system, where the phases have $\mathrm{NaCl}$ and NiAs structures, respectively, the interfacial planes were heteropolar (100) for FeO and homopolar (0001) for FeS.

Misorientations in twist and tilt of $6^{\circ}$ or less were observed between the phases in all the eutectic structures except the $\mathrm{NaBr}-\mathrm{NaF}$ system. The relative misorientations are shown schematically in Figs. 3 and 4.

\section{Discussion}

The noteworthy results are: (1) The identical crystal orientation of the two NaCl-type phases within a eutectic pair; and (2) the variation in growth directions for specific phases from one eutectic pair to another. Thus it is necessary to conclude that the crystal orientations were determined jointly by the phase pairs.

Previous studies on orientation of eutectics indicate a simultaneous edgewise growth of the lamellar phases in the directions of heat flow, as was verified experimentally by Straumanis and Brakss. ${ }^{16}$ Tiller $^{7}$ proposed that eutectic interface configurations consist of parallel crystallographic planes to minimize the solid-solid interfacial energy, thus reducing the depth of the interlamellar groove at the solidliquid solidification front. This would form a more nearly plane solidification front and facilitate lateral diffusion in the liquid ahead of the front. Thus, from the beginning, it seemed natural to assume that nucleation and growth would result in certain preferred crystallographic orientations and bounding planes for the lamellar eutectic phases. Many $\mathrm{X}$-ray diffraction studies have indicated that low index planes and directions of both phases of binary lamellar eutectics are orthogonally related to lamella interfaces and growth directions. ${ }^{4,12,13,17,18}$ There has been disagreement, however, as to precisely what were the orientations for a particular system. ${ }^{4,17}$ This is not completely unexpected, since studies of heterogeneous nucleation have shown many inconsistencies, due to impurity effects and also to the fact that more than one crystallographic orientation can be nucleated in a single system.

Penfold and Hellawell ${ }^{13}$ reported (111) lamellar interface planes and [110] growth directions for both $\mathrm{NaCl}-\mathrm{NaF}$ and LiF-NaF unidirectionally solidified eutectics. The LiF-NaF results of this study agree with their observations but the $\mathrm{NaF}-\mathrm{NaCl}$ results do not (Table I and Fig. 3).

Truelove and Hellawell ${ }^{14}$ also reported that $\mathrm{NaCl}$ precipitates as octahedra bounded by (111) planes in an $\mathrm{NaF}$ matrix with the same erystallographic orientation as the matrix. They indicate, however, that there is not an ex clusive preference for the homopolar habit planes among the

Table I. Summary of Crystallographic Relations

\begin{tabular}{lccc}
\hline \multicolumn{1}{c}{ Eutectic } & $\begin{array}{c}\text { Structure } \\
\text { types }\end{array}$ & $\begin{array}{c}\text { Interface } \\
\text { planes }\end{array}$ & $\begin{array}{c}\text { Growth } \\
\text { directions }\end{array}$ \\
\hline $\mathrm{MnO}-\mathrm{MnS}$ & $\mathrm{NaCl}-\mathrm{NaCl}$ & $(111)-(111)$ & {$[11 \overline{2}]-[11 \overline{2}]$} \\
$\mathrm{NaCl}-\mathrm{NaF}$ & $\mathrm{NaCl}-\mathrm{NaCl}$ & $(110)-(110)$ & {$[001]-[001]$} \\
$\mathrm{NaBr}-\mathrm{NaF}$ & $\mathrm{NaCl}-\mathrm{NaCl}$ & $(110)-(110)$ & {$[1 \overline{1} 1]-[1 \overline{1} 1]$} \\
$\mathrm{LiF}-\mathrm{NaF}$ & $\mathrm{NaCl}-\mathrm{NaCl}$ & $(1 \overline{1} 1)-(1 \overline{1} 1)$ & {$[110]-[110]$} \\
$\mathrm{FeO}-\mathrm{FeS}$ & $\mathrm{NaCl}-\mathrm{NiAs}$ & $(100)-(0001)$ & {$[011]-[10 \overline{10}]$} \\
\hline
\end{tabular}

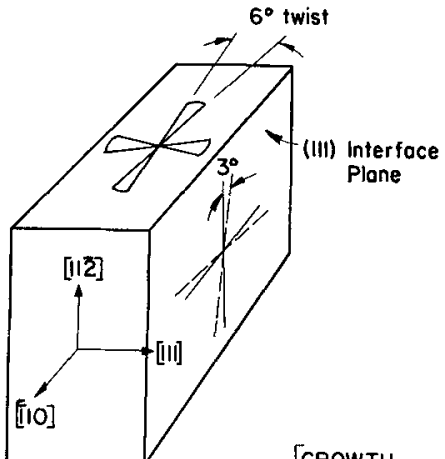

(a) MnO-MnS

[GROWTH

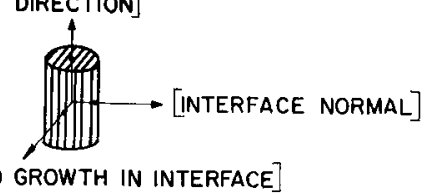

[NORMAL TO GROWTH IN INTERFACE]

(e) Orientation

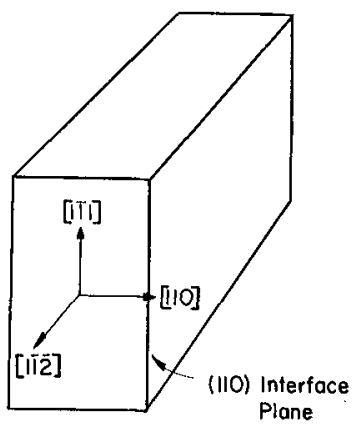

(c) $\mathrm{NaBr}-\mathrm{NaF}$

Fig. 3. NaCl-NaCl structure type eutectic pairs showing crystallographic orientations of each pair in relation to lamellar interfaces and growth directions of crystals. Small twist and tilt misorientations between phases are also noted.

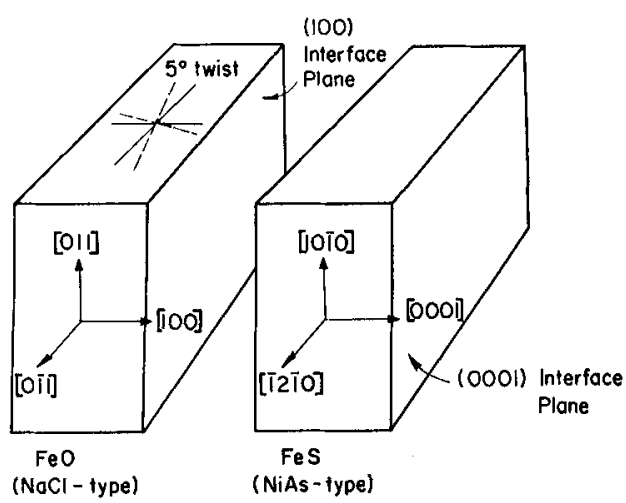

Fig. 4. NaCl-NiAs structure type eutectic pair of FeO-FeS showing crystallographic orientations of each phase in relation to their lamellar interface and growth direction. A $5^{\circ}$ tilt misorientation between the phases is also shown. (See Fig. 3 for orientation notation.) 
alkali halide systems. Again the differences noted may be due to impurity effects caused by variations in starting materials or crucibles. Crucibles in this work were spectrographic grade graphite; Hellawell and co-workers used recrystallized alumina crucibles.

Evidence indicates further that more than one crystallographic relation between phases can be nucleated in a single system. Sundquist and Mondolfo ${ }^{19}$ studied solidification undercooling and relative crystallographic phase orientations in self-nucleated eutectic alloys of lead and concluded that many orientation relations can occur, but that they usually involve low index planes with low linear lattice misfits when the crystal structures are simple. Since the lowest possible misfit was not always the most frequent orientation relation, these workers concluded that other factors were involved. Good symmetry relations between mating planes seemed to be a second important factor, corresponding to the findings in previous experiments on epitaxial overgrowth. ${ }^{20}$ The amount of observed undercooling did not seem to alter the orientation relations or lattice disregistries.

Although the results of the current study agree with the above requirements for low index direction interfaces and planes, the lattice mismatch between phases is significant (approximately 25 linear percent in the $\mathrm{NaF}-\mathrm{NaBr}$ eutectic pair), and we cannot conclude that the boundary energy is low. The matching orientations, however, permit octahedral coordinations of positive and negative charges across the boundary and a minimum of coulombic repulsion such as would be found with any misorientation of the two phases. Thus, in spite of the lattice mismatch and necessary dislocations and strain energy, the common orientation may still represent the lowest possible boundary energy. In effect, the two phases of the eutectic pair crystallize as a "single" ionic crystal with internal imperfections to accommodate the dimensional mismatch. Even so, slight twists and tilts result, as shown in Figs. 3 and 4.

It would be natural to predict that the matching planes in the FeO-FeS eutectic would be (111)-(0001) and homopolar rather than the observed (100)-(0001). There is, however, a difference in symmetry in the two phases of this system so that it is never really possible to have a "single" crystal as we did when the two phases of the eutectic pair had the same NaCltype crystal structure. Furthermore, the FeS must be more covalent to form the NiAs structure. The long range ionic coordination is thus no longer the governing factor and the dimensions become relatively more important. In the observed relation, the $\mathrm{Fe}-\mathrm{Fe}$ spacing along the $10 \overline{10}$ growth direction of FeS is $5,96 \mathrm{~A}$, or approximately twice the $\mathrm{Fe}-\mathrm{Fe}$ spacing of $3.04 \mathrm{~A}$ in the 011 growth direction of FeO. Other dimensions require $11.6 \mathrm{~A}^{2} / \mathrm{Fe}$ on the (0001) plane of $\mathrm{FeS}$ and $9.2 \mathrm{~A}^{2} / \mathrm{Fe}$ on the (100) plane of $\mathrm{FeO}$ so that the average linear mismatch between the two structures is $12 \%$. These factors apparently permit the observed FeO-FeS relation.

\section{References}

I W. G. Pfann, "Principles of Zone-Melting," J. Metals, 4, $747-53(1952)$

${ }^{2}$ J. W. Rutter and B. Chalmers, "Prismatic Substructure Formed During Solidification of Metals," Can. J. Phys., 31, 15$39(1953)$

${ }^{3}$ W. A. Tiller, K. A. Jackson, J. W. Rutter, and B. Chalmers, "Redistribution of Solute Atoms During Solidification of Metals," Acta Met., 1, 428-37 (1953).

${ }^{4}$ G. A. Chadwick, "Eutectic Alloy Solidification," Progr. Mater. Sci., 12 [2] 99-182 (1963).

5 W. A. Tiller and J. W. Rutter, "Effect of Growth Conditions Upon the Solidification of a Binary Alloy," Can. J. Phys., 34, 96-121 (1956).

${ }^{6}$ H. W. Weart and D. J. Mack, "Eutectic Solidification Structures," Trans. AIME, 212 [5] 664-70 (1958).

7 W. A. Tiller, "Polyphase Solidification," Liquid Metals and Soliditication, Seminar 39th Natl. Metal Congr., Chicago, 1957, pp. 276-318 (published 1958).

8 R. W. Kraft Jr, and D, L. Albright, "Microstructure of Unidirectionally Solidified Al-CuAl ${ }_{2}$ Eutectic," Trans. AIME, 221 [2] 95-102 (1961).

9 I. D. Hunt and K. A. Jackson, "Binary Eutectic Solidification," ibid., 236 [6] 843-52 (1966).

${ }^{10}$ K. A. Jackson and J. D. Hunt, "Lamellar and Rod Eutectic Growth," ibid., [8] 1129-42.

${ }^{11}$ I. G. Loxham and A. Hellawell "Constitution and Microstructure of Some Binary Alkali Halide Mixtures," $J . A m$. Ceram. Soc., 47 [4] 184-88 (1964).

${ }_{12}$ D. J. S. Cooksey, D. Munson, M. P. Wilkinson, and A. Hellawell, "Freezing of Some Continuous Binary Eutectic Mixtures," Phil. Mag., 10 [107] 745-69 (1964).

${ }_{13} \mathrm{D}$. Penfold and A. Hellawell, "Microstructures of Alkal Halide Eutectics LiF-NaF and NaF-NaCl," J. Am. Ceram. Soc., 48 [3] 133-35 (1965).

${ }_{14} \mathrm{P}$. Truelove and A. Hellawell, "Habit Planes Between Phases in Systems NaCl-NaF and LiF-NaF," Phil. Mag., 11 [114] 1309-13 (1965).

${ }_{16}$ H. C. Chao, L. Thomassen, and L. H. Van Vlack, "Deformation and Fracture of MnS Crystals," ASM Trans. Quart., 57 [2] $386-98$ (1964).

${ }^{16} \mathrm{M}$. Straumanis and N. Brakss, "Structure of the ZincCadmium Eutectic," Z. Physik. Chem., 30B, 117-31 (1935).

${ }_{17}$ E. C. Ellwood and K. Q. Bagley, "Structure of Eutectics," J. Inst. Metals, 76, 631-42 (1949-50).

${ }^{18}$ R. W. Kraft, "Crystallography of Equilibrium-Phase Interfaces in Al-CuAl Eutectic Alloys," Trans. AIME, 224 [1] 65-75 (1962)

${ }_{19}$ B. E. Sundquist and L. F. Mondolfo, "Orientation Relationships in Heterogeneous Nucleation of Solid Lead from Liquid Lead," ibid., 221 [3] 607-13 (1961)

${ }_{20} \mathrm{~J}$. H. van der Merwe, "Misfitting Monolayers and Oriented Overgrowth," Discussions Faraday Soc., No. 5, 201-14 (1949).

\title{
Phase Diagrams for the Systems Si-O and Cr-O
}

\author{
R. E. JOHNSON* and ARNULF MUAN \\ College of Earth and Mineral Sciences, The Pennsylvania State University, University Park, Pennsylvania 16802
}

Equilibrium studies in the systems $\mathrm{Si}-\mathrm{O}$ and $\mathrm{Cr}-\mathrm{O}$ at high temperatures indicate that no stable intermediate compounds exist between the metals and the oxides, $\mathrm{SiO}_{2}$ or $\mathrm{Cr}_{2} \mathrm{O}_{3}$, up to solidus temperatures. In both systems, there is a large concentration range of coexistence of two liquid phases above liquidus temperatures.

\section{Introduction}

$\mathrm{T}$ HE determination of high-temperature equilibria in systems containing metal and oxide phases coexisting in
Presented at the Seventieth Annual Meeting of The American Ceramic Society, Chicago, Ill., April 24, 1968 (Basic Science Division, No. 63-B-68). Received January 15, 1968; revised copy received March 15, 1968. Contribution No. 67-22 from College of Earth and Mineral Sciences, The Pennsylvania State University.

This work was sponsored by the American Iron and Steel Institute.

At the time this work was done the writers were, respectively, postdoctoral fellow and professor of Mineral Sciences, College of Earth and Mineral Sciences, The Pennsylvania State University.

* Now staff scientist, Chase Brass and Copper Company, Cleveland, Ohio 44122 . 